\title{
Cidadania e democracia: avanços e desafios da Ouvidoria Estadual de Saúde de Minas Gerais
}

Citizenship and democracy: progress and challenges of Health Ombudsman of Minas Gerais

\section{Fernando Antônio Gomes Leles}

Administrador Público, Especialista em Políticas Públicas e Gestão Governamental, Pós-graduado em Gestão e Economia da Saúde, Mestrando em Saúde Global e Diplomacia da Saúde. Secretaria de Estado de Saúde de Minas Gerais (SES/MG) e Organização Pan-Americana de Saúde (OPAS/OMS). Brasília, Brasil.

\section{Francisco Antônio Tavares Junior}

Secretário de Estado Adjunto de Saúde de Minas Gerais, Especialista em Planejamento em Saúde e Economia da Saúde. Secretaria de Estado de Saúde de Minas Gerais (SES/MG). Belo Horizonte, Brasil.

\section{Ana Piterman}

Odontóloga, Ouvidora de Saúde, Doutoranda em Saneamento, Meio Ambiente e Recursos Hídricos. Ouvidoria Geral do Estado de Minas Gerais (OGE/MG). Belo Horizonte, Brasil.

Resumo: No mundo contemporâneo observam-se profundas transformações nas relações entre sociedade civil e governos. A gestão pública, ao adotar novas formas de inclusão das demandas dos cidadãos nas políticas públicas e garantir melhor intermediação de interesses, aumenta a chance de obtenção de altos índices de representatividade entre os atores que se interagem. As ouvidorias fortalecem o SUS e a defesa do direito à saúde da população. Este artigo faz uma retomada do processo de implantação da Ouvidoria de Saúde em Minas Gerais, apresenta as principais características das demandas apresentadas pelos usuários a este canal e as estratégias desenvolvidas para ampliação deste instrumento de gestão para a cidadania. Vale ressaltar que a Saúde é a área de governo mais demandada $(28,8 \%$ do total), a maioria das demandas são "reclamação" (49,31\%), especialmente relacionadas a assuntos operacionais referentes a serviços de assistência à saúde (como dificuldades para conseguir atendimento e na marcação de exames/consultas) e a gestão (falta de profissionais e insatisfação). O forte aumento no número de manifestações recebidas ao longo dos anos pode demonstrar a ampliação da confiança do cidadão mineiro na Ouvidoria como importante interlocutor no processo de aprimoramento do sistema de saúde e das políticas públicas como um todo no Estado. A organização, disseminação e publicização de informações de forma instrumentalizada vem permitindo aos gestores análises quantitativas e qualitativas, apoiando a implantação de medidas corretivas e sugestões de correção. Outra importante ação que vem sendo desenvolvida é o projeto "Estado em Rede", que 
propõe a aproximação da população ao governo, por meio da participação democrática na priorização da ação governamental e no controle de sua implementação, através da constituição de colegiados intersetoriais para articulação horizontal e sistêmica.

Palavras-chave: Participação social, ouvidoria, saúde, cidadania, Estado em rede.

Key-words: Social participation, Ombudsman, Health, Citizenship, Integrated Government

No mundo contemporâneo vivenciamos profundas transformações nas relações da sociedade civil e os governos, existindo uma grande inquietação a respeito da defesa dos direitos humanos básicos.

A gestão pública, ao adotar novas formas de inclusão das demandas dos cidadãos nas políticas e garantir melhor intermediação de interesses, aumenta a chance de obtenção de altos índices de representatividade entre os atores que se interagem. No setor saúde brasileiro, e mais especificamente no Sistema Único de Saúde (SUS), a participação social é não apenas um instrumento, mas um princípio, tendo em vista o próprio processo de criação do SUS, por meio do movimento de reforma sanitária brasileiro, que mobilizou amplamente setores da sociedade civil organizada, da academia, da gestão e trabalhadores de saúde ao longo das décadas de 1970-80. Este movimento, somando ao processo de redemocratização do Brasil e elaboração da nova Constituição promulgada em 1988, culminou no entendimento de que a saúde é um direito social, sendo parte do conjunto de ações de Seguridade Social estabelecidos no Capítulo II da CRFB/1988. Em seus Artigos 196, 197 e 198, a CFRB/1988 determina um sistema de acesso universal e igualitário, a integralidade (por meio de ações e serviços de vigilância e atenção à saúde para sua promoção, proteção e recuperação), devendo ser organizado de forma regionalizada, hierarquizada e com a participação da comunidade (Art.198). Tal diretriz se baseia no princípio fundacional da democracia brasileira, segundo o qual "todo poder emana do povo, que o exerce por meio de representantes eleitos ou diretamente, nos termos desta Constituição" (Art. $1^{\circ}$, parágrafo único).

Portanto, desde sua "criação", por meio da Constituição Cidadã de 1988, e início de implantação, através das legislações básicas de inícios da década de 1990, a sociedade brasileira é chamada a participar do SUS. Esta participação deve ser 
entendida como algo bastante mais amplo que o simples "controle social", que, embora amplamente utilizado tanto em documentos oficiais, quanto nas falas quotidianas, pode ser considerado um reducionismo por não ser expressão da amplitude do direito constitucional, indo para além do controle e fiscalização da aplicação dos recursos financeiros, mas sendo exercido também através da proposição e participação na formulação das políticas, em seu acompanhamento e avaliação. Desta forma, a participação da comunidade no SUS se dá em especial através de três grandes instituições: os Conselhos de Saúde, as Conferências de Saúde e as Ouvidorias.

Os Conselhos e as Conferências de Saúde foram estabelecidos pela Lei nº 8142, de 28 de dezembro de 1990. Conforme expresso em seu art.1ํㅡ, estas duas instâncias colegiadas devem ser organizadas nas três esferas de governo, conforme o Quadro 1.

Quadro 1: Instâncias da Gestão Democrática e Participativa do SUS.

\begin{tabular}{|c|c|c|c|c|}
\hline $\begin{array}{c}\text { ESFERA DE } \\
\text { GOVERNO }\end{array}$ & $\begin{array}{c}\text { GESTOR DO } \\
\text { SUS }\end{array}$ & $\begin{array}{c}\text { ARENAS DE NEGOCIAÇÃO } \\
\text { DE GESTÃO }\end{array}$ & \multicolumn{2}{|c|}{$\begin{array}{c}\text { PARTICIPAÇÃO DA } \\
\text { COMUNIDADE }\end{array}$} \\
\hline \multirow{2}{*}{ União } & $\begin{array}{c}\text { Ministério da } \\
\text { Saúde (MS) }\end{array}$ & $\begin{array}{c}\text { Comissão Intergestores } \\
\text { Tripartite (CIT) }\end{array}$ & $\begin{array}{c}\text { Conselho } \\
\text { Nacional de } \\
\text { Saúde (CNS) }\end{array}$ & $\begin{array}{c}\text { Conferência } \\
\text { Nacional de } \\
\text { Saúde }\end{array}$ \\
\hline \multirow{2}{*}{ Estados } & $\begin{array}{c}\text { Secretaria de } \\
\text { Estado de } \\
\text { Saúde (SES) }\end{array}$ & $\begin{array}{c}\text { Comissão Intergestores } \\
\text { Bipartite (CIB) }\end{array}$ & $\begin{array}{c}\text { Conselho } \\
\text { Estadual de } \\
\text { Saúde (CES) }\end{array}$ & $\begin{array}{c}\text { Conferência } \\
\text { Estadual de } \\
\text { Saúde }\end{array}$ \\
\hline \multirow{2}{*}{ Municípios } & Secretaria & Colegiados de Gestão & Conselho \\
& Municipal de & Conipal de & Conferência \\
& Saúde (SMS) & Regional (CGR) & Saúde (CMS) & Saúde \\
\hline
\end{tabular}

Fonte: Elaboração dos autores.

Os Conselhos de Saúde têm caráter permanente e deliberativo, são órgãos colegiados "paritários", compostos $50 \%$ por usuários e $50 \%$ de representantes do governo, prestadores de serviços e profissionais de saúde (Lei $n^{\circ}$ 8142/1990, art. 1ํㅡ, $\S \S 1^{\circ o}$ e $4^{\circ}$ ). Seu objetivo é a formulação de estratégias e diretrizes para a política pública de saúde, o acompanhamento de sua execução, incluindo os aspectos financeiros e orçamentários, e a avaliação dos resultados sanitários alcançados. Para além da obrigação legal, vários municípios, em especial aqueles mais populosos, organizam comissões ou conselhos locais, no âmbito das unidades de saúde.

As Conferências de Saúde têm o objetivo de "avaliar a situação de saúde e propor as diretrizes para a formulação da política de saúde" (Lei № 8142/1990, art. 1ํㅗ $§ 1^{\circ}$ ). 
Portanto, tratam-se do espaço de democracia direta na construção da política de saúde. Devem ser convocadas pelo Poder Executivo e pelo Conselho de saúde a cada 4 anos e delas devem sair as diretrizes para a formulação dos Planos de Saúde. Para isso, devem contar com a participação dos vários seguimentos sociais: a população, através dos usuários ou entidades da sociedade civil organizada, os trabalhadores da saúde, através dos sindicatos, associações, conselhos profissionais e de servidores públicos, prestadores de serviços de saúde e gestores do SUS. É fortemente recomendável que mesmo as conferências municipais sejam antecedidas de pré-conferências nas regiões, distritos e bairros, buscando uma participação ampla, transparente e ascendente.

As ouvidorias em saúde são instrumentos da gestão pública e do controle social para o aperfeiçoamento da qualidade e da eficácia das ações e serviços prestados pelo SUS (Ministério da Saúde, 2005). Desta forma, fortalecem o SUS e a defesa do direito à saúde da população por meio do incentivo à participação popular e da inclusão do cidadão diretamente no controle social, trazendo para dentro da gestão as opiniões, colaborações, avaliações, críticas e sugestões dos usuários. Para tal, o instituto da ouvidoria deve buscar promover o acesso e a melhoria da qualidade da atenção à saúde e a informação.

Historicamente, é possível dizer que as ouvidorias têm seus primórdios na Suécia do século XVIII, com os objetivos de vigilância e aprimoramento da Administração Pública diretamente pelos cidadãos, através de queixas, reclamações e sugestões dirigidas a um funcionário especialmente instituído pelo estado. Ao longo dos séculos, sua ampla disseminação (em especial no ocidente) e os processos culturais de difusão deste instrumento democrático de mediação, levaram ao desenvolvimento de uma multiplicidade de formas e modos de organizar e agir, gerando desde mecanismos simples de escuta direta a complexos arranjos institucionais, que incluem ações transversais e a especialização temática.

No Brasil, a Ouvidoria Geral do SUS foi criada através do Decreto nำ4726, de 9 de junho de 2003, com o objetivo de "propor, coordenar e implementar a Política Nacional de Ouvidoria em Saúde no âmbito do SUS, buscando integrar e estimular práticas que ampliem o acesso dos usuários ao processo de avaliação das ações e serviços públicos de saúde", além de integrar e potencializar vários serviços existentes àquele momento no Ministério da Saúde (como o "Serviço de Atendimento ao Cidadão Usuário do SUS", o "Disque Saúde" e o Centro Nacional de Promoção da Qualidade e Proteção ao Usuário do SUS), nos Estados e Municípios. 
Em Minas Gerais, a Ouvidoria-Geral do Estado (OGE) foi criada em 2004 com a missão de "ouvir, acompanhar e responder às manifestações dos cidadãos e apresentar aos dirigentes máximos dos órgãos e ao Governador as demandas apontadas pela população em relação aos serviços públicos". Sua visão é "contribuir para o alcance da excelência da gestão na administração do Estado por meio da vocalização dos anseios do cidadão em relação aos serviços públicos em Minas Gerais". Para isso, o órgão é vinculado diretamente ao Governador do Estado, exerce seu papel de forma autônoma em relação às secretarias executivas a quem deve fiscalizar e auxiliar no aprimoramento dos serviços prestados a partir da visão dos cidadãos. A OGE é composta de um Ouvidor-Geral, um Ouvidor Adjunto e 6 ouvidores especializados em a)Saúde, b)Educação, c)Meio-ambiente, d)Polícia, e)Sistema penitenciário e f)Fazenda, patrimônio e licitações públicas. A instituição possui autonomia administrativa, orçamentária e financeira, bem como autonomia nas suas decisões técnicas (inclusive em relação à gestão estadual do SUS). Os dirigentes têm mandato fixo e estabilidade não existindo subordinação hierárquica a nenhum dos Poderes do Estado ou seus membros e sendo as suas decisões terminativas em última instância administrativa.

Conforme o relatório oficial extraído do "Sistema de Ouvidoria e Gestão Pública Tomás Antônio Gonzaga", entre janeiro e junho de 2013 a OGE recebeu 10.243 manifestações. Isso representa um crescimento de 78,76\% em relação ao 1ํㅗ semestre de 2012, sendo cerca de 1.707 manifestações/mês em 2013. A distribuição das manifestações segundo a especialidade pode ser vista na Tabela 1, a seguir.

Tabela 1: Número de manifestações recebidas pela Ouvidoria Geral do Estado, segundo Ouvidoria Especializada. Minas Gerais, jan./jun., 2013.

\begin{tabular}{lcc}
\hline $\begin{array}{l}\text { Ouvidoria } \\
\text { Especializada }\end{array}$ & Manifestações & $\begin{array}{c}\text { Distribuição } \\
\text { Relativa (\%) }\end{array}$ \\
\hline Saúde & 2.951 & 28,8 \\
\hline Educacional & 2.400 & 23,4 \\
\hline Polícia & 2.082 & 20,3 \\
\hline Fazenda & 1.096 & 10,7 \\
\hline Sistema Penitenciário & 944 & 9,2 \\
\hline Ouvidora Geral Adjunta & 468 & 4,6 \\
\hline Ambiental & 302 & 2,9 \\
\hline Total & 10.243 & 100,0
\end{tabular}


As manifestações podem ser registradas pelos cidadãos presencialmente, via internet (site da OGE ou e-mail), por telefone (Disque-Ouvidoria 162), por carta e por fax. A maior parte das manifestações foi registrada no site da OGE (52\%) e via telefone (30\%). Quanto à tipologia, as manifestações recebidas pela OGE são classificadas como denúncias, reclamações, solicitações, críticas, informações, sugestões e elogios. No $1^{\circ}$ semestre de 2013, cerca de $39 \%$ das manifestações foram "reclamações", em $2^{\circ}$ lugar as "denúncias" $(35,76 \%)$ e as "solicitações de informação" (11,48\%). Do total de 10.243 manifestações, 65\% já foram encerradas e $35 \%$ estão em andamento.

A Ouvidoria de Saúde tem por finalidade "receber e encaminhar denúncias, reclamações, sugestões, críticas, solicitações e elogios relativos ao serviço público de saúde prestado por órgão ou entidade pública ou por seus conveniados", assim como "acompanhar a tramitação e a análise das demandas recebidas e transmitir as soluções dadas ao manifestante ou a seu representante legal" (MINAS GERAIS, 2013a). Em caso de indícios de ilegalidade, cabe-lhe realizar vistorias em órgãos ou entidades públicas, propondo medidas para aprimoramento da organização e das atividades.

A Ouvidoria de Saúde trabalha de forma integrada à OGE/MG e à Ouvidoria Geral do SUS. Por esta razão, trabalha com duas ferramentas informatizadas: o "Sistema de Ouvidoria e Gestão Pública Tomás Antônio Gonzaga" (TAG-OGE/MG) e o "Sistema Ouvidor SUS" (da Ouvidoria Geral do SUS).

No $1^{\circ}$ semestre de 2013, foram recebidas 2.951 manifestações. Esse número é $154 \%$ superior ao observado no $1^{\circ}$ sem/2012, que foi de 1.162. O Gráfico 1 apresenta a evolução no número de manifestações de 2007 ao $1^{\circ}$ semestre de 2013, onde pode-se observar um movimento de crescimento na quantidade de demandas desde 2011, mas que foi fortemente acelerado nos anos 2012 e 2013. Esse forte crescimento pode ser atribuído a vários fatores subjetivos aos cidadãos (expectativas e percepções), e institucionais, como um esforço na sensibilização dos municípios no sentido de criar ouvidorias de saúde, da ampliação da visibilidade dos canais de ouvidoria no estado e à estratégia de "ouvidorias móveis", empreendida entre os meses de março e abril. 
Gráfico 1: Manifestações recebidas pela Ouvidoria de Saúde. Minas Gerais, 2007-2013.

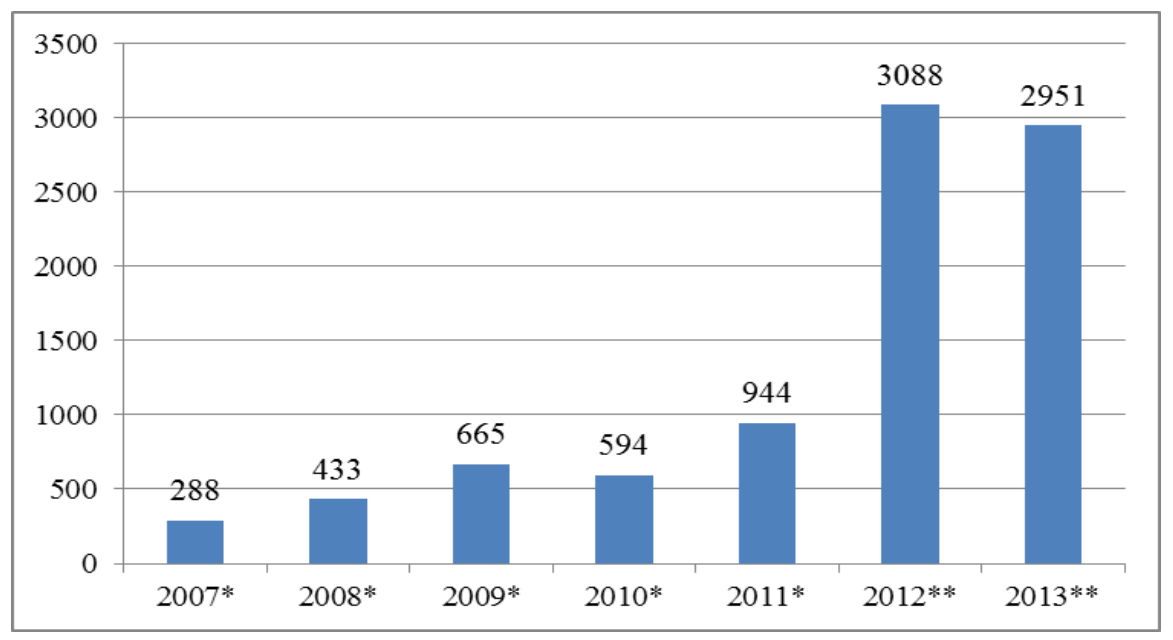

Fontes: *MINAS GERAIS (2013b) e **MINAS GERAIS (2013a)

Note-se que, devido ao início do funcionamento do sistema Ouvidor SUS apenas em novembro de 2011, os dados apresentados no Gráfico 1, para os anos 2007-2011 são provenientes apenas do sistema "TAG-OGE/MG". Já a partir de 2012 aos dados desse sistema foram somados os registrados no Sistema Ouvidor SUS do Ministério da Saúde.

Em relação à tipologia das manifestações, observa-se que em 2013 quase metade delas referiu-se a "Reclamação" (49,31\%). Tal fato pode ser atribuído, a priori, tanto a uma maior expectativa dos cidadãos em relação aos serviços de saúde, quanto a uma pior percepção desse serviço pelos usuários. Contudo, tais conclusões carecem de pesquisas definitivas.

Gráfico 2: Manifestações recebidas pela Ouvidoria de Saúde, segundo tipologia. Minas Gerais, 1ํㅗㄹ semestre de 2013.

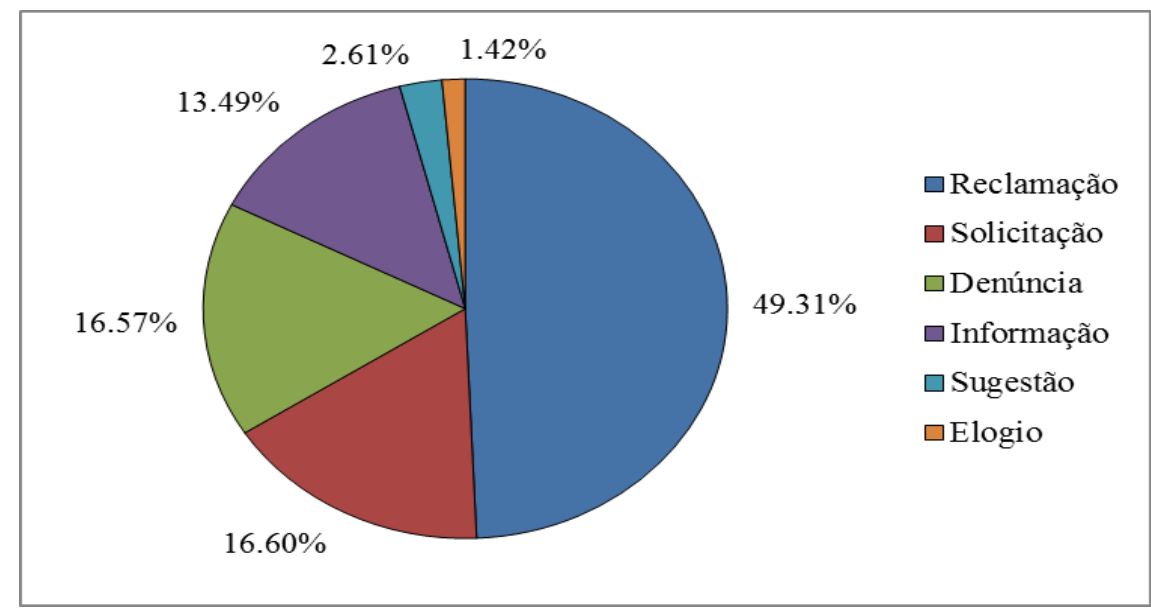

Fonte: MINAS GERAIS (2013a) 
De toda forma, é interessante registrar que foram recebidos 42 "elogios" e 77 "sugestões", o que demonstra tanto a compreensão mais ampla do papel da Ouvidoria por parte dos usuários, quanto a disponibilidade destes em participar da construção das políticas de saúde no estado.

Por ser o canal de mais fácil acesso da população, mesmo em um estado com tão grandes desigualdades regionais no desenvolvimento e acesso a serviços como é o caso de MG, a maior parte das manifestações foi registrada via internet, com grande preponderância do "site" (63,3\%). Em $2^{\circ}$ lugar, vêm os registros por "telefone" $(27,75 \%)$ e "presenciais" (6,4\%). As demandas via cartas, ofícios e fax representam, somadas, cerca de $1 \%$.

Por se tratar de um órgão estadual, a jurisdição da Ouvidoria de saúde compreende os 853 municípios mineiros. Durante o $1^{\underline{0}}$ semestre de 2013, foram recebidas manifestações provenientes de 487 municípios (57\% do total de 853 de $M G)$. Os dados apresentam uma grande concentração das manifestações: enquanto a maioria dos municípios (82,4\%) receberam até 5 manifestações em 2013, apenas 15 municípios receberam mais de 25.

Ressalta-se que, isoladamente, do município de Belo Horizonte são provenientes 644 manifestações $(21,8 \%$ do total). Levando-se em consideração que a população da Capital representa apenas $12,1 \%$ da população total de MG, esta forte concentração de manifestações pode, a um primeiro momento, dar a entender que o sistema de saúde da Capital seria alvo de mais manifestações que o interior do estado. Contudo, há que se ponderar que o município também, conta com uma rede de serviços de saúde mais extensa, assim como um maior acesso a informação e tecnologia, fatos que poderiam gerar uma maior "exposição" do sistema a críticas.

Com o objetivo de melhor subsidiar os gestores na elaboração e implantação de medidas corretivas e de monitorar o desenvolvimento do sistema de saúde, a Ouvidoria de Saúde classifica as manifestações recebidas segundo sua natureza em "Assuntos transversais" e "Assuntos operacionais". Dentre as manifestações recebidas no $1^{\circ}$ semestre de 2013, apenas 2,5\% (75 manifestações) foram consideradas como "assuntos transversais". Neste caso, as manifestações se concentram em "não cumprimento integral de carga horária" (35\%). Outros assuntos transversais têm uma menor magnitude: "insatisfação com as normas vigentes" (8\%), 
"mau atendimento" (6,7\%), "Elogio ao atendimento ao cidadão" (5,3\%), "Utilização indevida de veículo oficial" (5,3\%).

Já as manifestações classificadas como "Assuntos operacionais" representaram 97,5\% do total e são subdivididas em 19 áreas, cuja distribuição das ocorrências se encontra na Tabela 2.

Tabela 2: Assuntos operacionais demandados nas manifestações recebidas pela Ouvidoria de Saúde. Minas Gerais, 1ํ semestre de 2013.

\begin{tabular}{lc}
\hline \multicolumn{1}{c}{ Assuntos operacionais } & $\%$ \\
\hline Serviço de assistência à saúde & 52,07 \\
\hline Gestão & 22,47 \\
\hline Assistência farmacêutica & 9,89 \\
\hline Farmácia Popular & 7,30 \\
\hline Estratégia Saúde da Família/PACS & 3,57 \\
\hline Vigilância Sanitária & 1,05 \\
\hline Assistência odontológica & 0,73 \\
\hline Material hospitalar & 0,57 \\
\hline Alimento & 0,49 \\
\hline Solicitação de auditoria em unidade de saúde & 0,49 \\
\hline Programa de controle do tabagismo & 0,32 \\
\hline Esclarecimentos sobre a manifestação do cidadão & 0,24 \\
\hline Serviço de Atendimento Móvel de Urgência (SAMU) & 0,24 \\
\hline Transporte & 0,16 \\
\hline Dificuldade de acesso à unidade de saúde & 0,16 \\
\hline Cartão SUS & 0,08 \\
\hline Dificuldade de acesso ao programa de saúde & 0,08 \\
\hline Vagas em unidade de saúde & 0,08 \\
\hline Total & $\mathbf{1 0 0 , 0 0}$ \\
\hline Fonte:MINAS GERAIS (2013a) &
\end{tabular}

Fonte: MINAS GERAIS (2013a)

Conforme se pôde ver, a grande maioria das manifestações classificadas como "Assuntos Operacionais" se refere a apenas duas áreas: "Serviço de assistência à saúde" (52,07\%) e "Gestão" (22,47\%). É possível que esta concentração reflita um "desequilíbrio" entre as categorias no que se refere a suas respectivas abrangências.

Um detalhamento das manifestações classificadas na área de "Serviço de assistência à saúde" mostra que as reclamações se referem principalmente a dificuldades de acesso aos serviços (marcação de exames e consultas, conseguir 
atendimento, cirurgias e TFD). Além disso, há procura por informações, como orientações de saúde e sobre produtos.

No caso das manifestações classificadas como "Gestão", observa-se que se concentram em reclamações relacionadas a recursos humanos (insatisfação e falta de profissionais, respondendo por quase $70 \%$ ) e relativas à gestão dos estabelecimentos de saúde (cerca de 25\%).

Das manifestações registradas no $1^{\circ}$ semestre de 2013, no sistema TAG, $60,86 \%$ já haviam sido encerradas quando da publicação do Relatório Semestral, em 29/ago/2013, e 39,14\% encontravam-se em andamento. Contudo, cerca de $45 \%$ das manifestações registradas em 2012 e 5 manifestações de 2011 ainda estão em andamento, já tendo extrapolado os prazos legais de resposta.

No início de 2011, constatou-se um passivo de 1.500 ausências de respostas a manifestações provenientes dos cidadãos. Além disso, a análise daquelas consideradas respondidas indicava grande morosidade ou baixa qualidade. Com o intuito de melhorar o desempenho da Ouvidoria em Saúde e atender à crescente demanda observada nos anos subsequentes, foi celebrada uma forte parceria entre os órgãos estaduais (Ouvidoria de Saúde, Secretaria de Estado de Saúde - nível central e Unidades Regionais -, Ipsemg, Fhemig, Hemominas, IPSM, Funed e SEPLAG) e os gestores municipais, sendo conformada uma rede estadual que é permanentemente demandada pela Ouvidoria. A distribuição relativa das manifestações entre os parceiros mais demandados em Minas Gerais mostra que, em boa medida, há concentração das demandas na Capital e Região Metropolitana (Unidade Regional de Saúde de Belo Horizonte/SESMG), além das regiões Norte de Minas (UR Montes Claros/SESMG), Triângulo do Norte (UR Uberlândia/SESMG) e Sul de Minas (URs Pouso Alegre e Varginha/SESMG).

O forte aumento no número de manifestações recebidas ao longo dos anos pode demonstrar a ampliação da confiança do cidadão mineiro na Ouvidoria como importante interlocutor no processo de aprimoramento do sistema de saúde e das políticas públicas como um todo no Estado. É interessante notar que a proporção de identificação dos autores das manifestações é maior quando se dirigem à Ouvidoria de Saúde (76,31\%), em comparação aos demais $(58,27 \%)$. Tal fato pode se dar devido ao sentimento e à necessidade de ter seu caso pessoal sendo resolvido pelo instituto. 
Gráfico 3: Situação de identificação do autor das manifestações recebidas pela Ouvidoria Geral do Estado e pela Ouvidoria de Saúde. Minas Gerais, 1ํsem/2013.

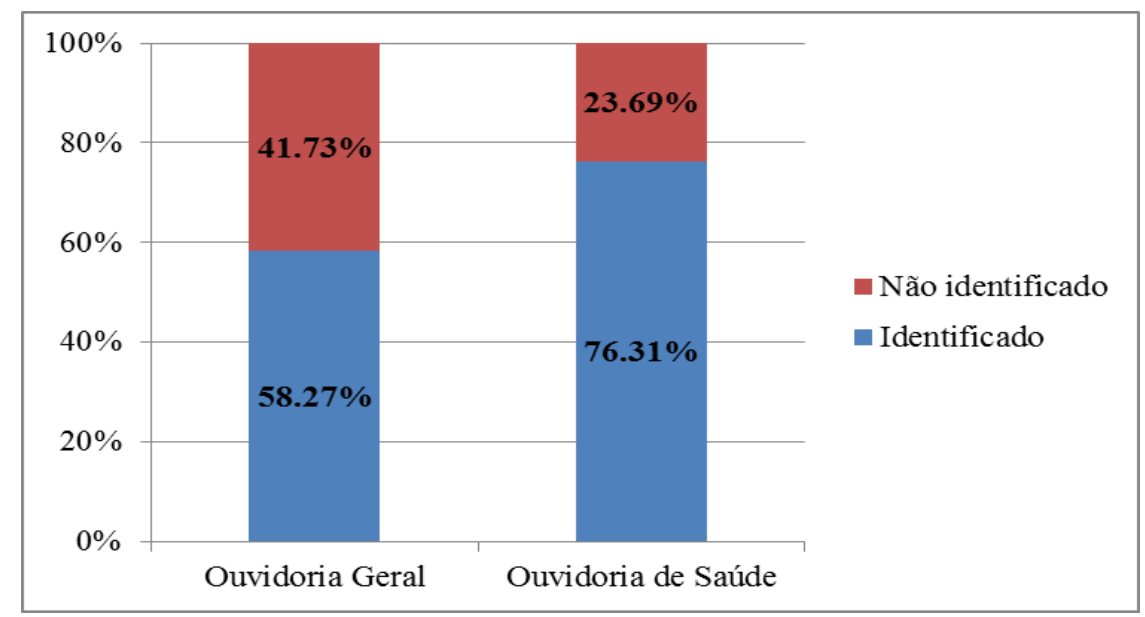

Fonte: MINAS GERAIS (2013a).

Contudo, é interessante a relação inversa ao se tomar os dados referentes à solicitação de sigilo da identidade do autor. Neste caso, há uma maior proporção de autores que preferem que sua identidade não seja revelada no caso da saúde. Talvez esse fato se dê devido ao medo de represálias, como negativas de atendimento ou maus tratos em necessidades futuras. Tais comportamentos merecem melhor e mais criteriosa análise em estudos posteriores.

A organização, disseminação e publicização das informações de forma instrumentalizada vem permitindo uma análise não apenas quantitativa, mas também qualitativa, dando visibilidade às medidas corretivas e sugestões de correção. A publicização dos processos de forma eletrônica é uma importante ferramenta para favorecer "as mudanças e ajustes nas atividades e processos desenvolvidos no setor público em sintonia com as demandas da sociedade", rumo à efetivação da qualidade, da transparência e da cidadania, evitando que "haja reincidências sistemáticas de assuntos relativos à ineficiência da prestação de serviços públicos, do atendimento realizado pelas instituições ou mesmo de irregularidades cometidas por gestores, servidores e/ou atendimento e serviços que lhes foram prestados" (Minas Gerais, 2013).

Buscando instrumentalizar a rede para a compreensão do papel da ouvidoria e aprimorar o diálogo entre os cidadãos e as instituições de saúde, foi concebido e empreendido um amplo projeto de formação. Através do Portal Minas Saúde, no período de jun-ago/2012, foi realizada a $1^{\text {a }}$ edição de um curso de extensão à 
distância, com 80h, destinado a 2000 profissionais da própria SES (central e regionais), Ouvidoria, municípios (gestor municipal e um técnico), Conselho Estadual de Saúde. Os resultados foram bastante encorajadores, com um aumento na quantidade de respostas, uma redução no tempo de resposta e, mais importante, uma forte melhoria qualitativa. A $2^{\underline{a}}$ edição do curso está acontecendo no período de set-nov/2013.

Outra importante ação que vem sendo desenvolvida é o projeto "Estado em Rede", que propõe a aproximação da população em relação ao governo, por meio da participação democrática no controle e na priorização da ação governamental. O projeto busca contemplar as particularidades e necessidades regionais, através da constituição de colegiados intersetoriais para articulação horizontal e sistêmica entre os diversos órgãos e entidades da administração pública na discussão e priorização de estratégias junto à sociedade civil organizada e atores estratégicos, como universidades locais e associações de municípios. Estes Fóruns Regionais devem produzir uma "Agenda Regional" e um plano de ação integrado, cuja execução deverá ser acompanhada em reuniões periódicas.

\section{Referências}

BRASIL. Constituição da República Federativa do Brasil (1988). Brasília, 1988. Disponível http://www.planalto.gov.br/ccivil 03/constituicao/constituicaocompilado.htm . Acesso em 15/ago/2013.

BRASIL. Lei $n^{\circ}$ 8080, de 19 de setembro de 1990. Dispõe sobre as condições para a promoção, proteção e recuperação da saúde, a organização e o funcionamento dos serviços correspondentes e dá outras providências. Brasília, 1990. Disponível em http://www.planalto.gov.br/ccivil 03/leis/l8080.htm. Acesso em 15/ago/2013.

BRASIL. Lei no 8142, de 28 de dezembro de 1990. Dispõe sobre a participação da comunidade na gestão do Sistema Único de Saúde (SUS) e sobre as transferências intergovernamentais de recursos financeiros na área da saúde e dá outras providências. $\quad$ Brasília, $1990 . \quad$ Disponível $\quad$ em http://portal.saude.gov.br/portal/arquivos/pdf/Lei8142.pdf. Acesso em 15/ago/2013.

BRASIL. Decreto no 4726, de 9 de junho de 2003. Aprova a Estrutura Regimental e o Quadro Demonstrativo dos Cargos em Comissão e das Funções Gratificadas do Ministério da Saúde, e dá outras providências. Brasília, 2003. Disponível em http://portal.saude.gov.br/portal/arquivos/pdf/decreto 47262003 estrutura ms.pdf.

Acesso em 15/ago/2013.

CONASEMS. Participação Social no SUS: O olhar da gestão municipal. Brasília: Conselho Nacional de Secretarias Municipais de Saúde, 2009, 28p. Disponível em 
http://bvsms.saude.gov.br/bvs/publicacoes/participacao social olhar gestao municip al.pdf Acesso em 15/ago/2013.

MINAS GERAIS. Ouvidoria Geral do Estado de Minas Gerais - Relatório Estatístico Semestral - 1ํ Semestre de 2013. Belo Horizonte: mimeo, 2013.

MINAS GERAIS. Ouvidoria Geral do Estado de Minas Gerais - Relatório Estatístico Temático da Ouvidoria de Saúde. Belo Horizonte: Diretoria de Análise Estatística e Informação/OGE/MG, 2013.

MINISTÉRIO DA SAÚDE. Série Histórica do CNS; n. 1, Brasília: Ministério da Saúde, $2002 . \quad 60 \quad$ p. $\quad$ Disponível em: http://conselho.saude.gov.br/biblioteca/livros/A Pratica Controle Social.pdf. Acesso em 15/ago/2013.

MINISTÉRIO DA SAÚDE. Oficina de Ouvidorias do SUS. Brasília: Ministério da Saúde, 2005, 76 p. (Série D. Reuniões e Conferências). Disponível em http://portal.saude.gov.br/portal/arquivos/pdf/oficina ouvidorias SUS.pdf Acesso em 15/ago/2013.

MINISTÉRIO DA SAÚDE, Portaria no 1820, de 13 de agosto de 2009. Dispõe sobre direitos e deveres dos usuários do SUS. Brasília, 2009. Disponível em http://bvsms.saude.gov.br/bvs/saudelegis/gm/2009/prt1820 1308 2009.html. Acesso em 15/ago/2013. 